\title{
A língua inglesa nas escolas de tempo integral: diretrizes e práticas de ensino ${ }^{1}$
}

\author{
Daniela Morales Monteiro $^{2}$
}

\begin{abstract}
RESUMO
Este artigo discute os resultados de uma pesquisa, que assumiu como objeto de estudo o ensino de língua inglesa nas escolas de tempo integral da rede pública de ensino do Estado de São Paulo. Os objetivos foram: entender como acontece esse ensino e as políticas públicas que o orientam; discutir a possibilidade de inclusão da língua inglesa nos anos iniciais do ensino fundamental e verificar as condições necessárias para que o ensino da língua estrangeira promova a equidade social. Para alcançar tais objetivos, foi realizada uma revisão de literatura, complementada por entrevista semiestruturada com docentes que atuam nessa área. Os dados da pesquisa revelam que o ensino da língua inglesa desperta grande interesse nos alunos dos anos iniciais. No entanto, foram evidenciados alguns fatores que não contribuem para que o ensino de línguas seja efetivo, por exemplo, a falta de recursos didáticos e a falta de formação para os professores.
\end{abstract}

Palavras-chave: ensino, escola pública, língua estrangeira.

\section{ABSTRACT}

This article discusses the results of a survey that took over as the object of study English-language teaching in all-day state public schools of São Paulo. The aim were to understand how this teaching has been developed and public policies and laws that guide; discuss the possibilities of inclusion of foreign language in the early years of elementary school and check the necessary conditions for the foreign language teaching promotes social equity. To achieve the objectives a literature review was made complemented by semi-structured interviews with teachers working in these schools. The survey data reveal that the teaching of English promotes great interest in students of the early years. However, were evidenced some factors that do not contribute to the effective language learning, for example, the lack of teaching resources and the lack of continuing formation for teachers.

Keywords: education, public school, foreign language

1 Este artigo é um recorte da minha dissertação de mestrado, defendida em março de 2014, sob orientação do Prof. Dr. Júlio Gomes Almeida. Aproveito para agradecer a SEE (Secretaria de Educação do Estado de São Paulo) pelo apoio financeiro e a Capes que possibilitou o aprimoramento dos meus estudos no Institute of Education in London.

2 Mestre em Educação pela Universidade Cidade de São Paulo. Possui aperfeiçoamento em Metodologia para o ensino de Língua Inglesa pelo I.O.E - Institute of Education in London. Pesquisadora dos grupos de pesquisa "Ensino de Língua Estrangeira, Formação Cidadã e Tecnologia" pela UNICAMP e "Grupos, Práticas e Formação" pela Unicid. Professora titular de língua inglesa na rede estadual de ensino de São Paulo. E-mail: moralesdani@bol.com.br 


\section{Introdução}

Em busca de atender as necessidades de um mundo globalizado, atualmente, é impreterível o domínio da língua inglesa. Com isso, as escolas privadas e públicas estão proporcionando o acesso ao ensino da língua inglesa cada vez mais cedo.

Nessa perspectiva (ALMEIDA FILHO, 1991) confirma que o domínio de uma língua estrangeira no contexto atual possibilita entender e participar do mundo em que se vive, a aprendizagem de LE aproxima os alunos de realidades distantes da realidade em que vivem, e possibilita o acesso ao conhecimento cultural de outros povos. Contextualiza o aluno, apenas exposto a uma realidade local a um acesso ao conhecimento cultural de outros povos.

Na rede estadual de ensino de São Paulo, até o presente momento, as línguas estrangeiras não integram oficialmente a matriz curricular dos anos iniciais do ensino fundamental. $\mathrm{O}$ Estado vem possibilitando acesso de seus alunos à língua estrangeira nos primeiros anos dessa etapa da Educação Básica, apenas nas Escolas de Tempo Integral. Com essa proposta, atende-se apenas a uma pequena parte dos alunos que frequentam o Ensino Fundamental (ciclo I) na rede estadual, excluindo a maioria dos alunos do ensino público.

Por outro lado, o Sistema Municipal de Ensino de São Paulo incluiu, em 2012, a língua inglesa em suas matrizes curriculares do ensino fundamental (ciclo I), promovendo o acesso ao ensino de língua estrangeira.

Ao discutir a questão do ensino de língua estrangeira na escola pública, Rocha (2009) salienta que o ensino da língua inglesa nos anos iniciais do ensino fundamental das redes públicas brasileiras é socialmente relevante à luta por maior equidade, à promoção do protagonismo social, bem como à construção da cidadania crítica e de bases multiculturais.

Ao considerar a importância da abordagem do ensino de língua estrangeira com crianças que iniciam os estudos curriculares obrigatórios, bem observou a Secretaria de Educação do Estado de São Paulo, que traçou os princípios da Proposta Curricular do Estado de São Paulo (2009), que diz: "Na sociedade de hoje, são indesejáveis, tanto a exclusão pela falta de acesso a bens materiais, quanto à exclusão pela falta de acesso ao conhecimento e aos bens culturais". Contudo a própria Secretaria não vem garantindo a todos esse direito que garante a inclusão que ela própria preconiza.

Nesse contexto, o artigo foca nos resultados revelados na pesquisa de campo, obtidos por meio de entrevista com questões semiestruturadas, realizadas com docentes que atuaram nas oficinas de língua inglesa no ano de 2013, nas escolas de tempo integral da rede estadual de ensino.

\section{A língua inglesa nas escolas de tempo integral: aspectos conceituais}

O projeto Escola de Tempo Integral, desenvolvido no Estado de São Paulo, foi instituído em dezembro de 2005, com o objetivo de oferecer aos estudantes do ensino fundamental (ciclo I) a oportunidade de estender o tempo de exposição às atividades que propiciem o aprendizado, o que veio atender aos anseios da sociedade e materializar um importante instrumento de política de inclusão. 
Nas considerações da resolução, que trata dos pormenores da aplicação do projeto, levou-se em conta a necessidade da educação, que desempenha papel relevante na dinâmica da sociedade, em especial, no dia a dia de crianças e jovens.

O programa previa ainda a organização de um currículo voltado a atender e orientar os alunos nas matérias básicas curriculares, desenvolver atividades artísticas e culturais no ambiente escolar, o fomento de atividades esportivas e de integração social, além de outras atividades complementares de enriquecimento curricular, dentre as quais, cita-se as oficinas curriculares de língua inglesa.

No que tange à matriz curricular, as aulas das oficinas de língua inglesa foram implantadas desde o início do projeto, com carga horária de duas aulas semanais, do primeiro ao quinto ano do ensino fundamental.

No entanto, houve, em 2013, uma alteração na matriz que excluiu os três primeiros anos das aulas de língua inglesa.

Observa-se que, se houvesse parâmetros estabelecidos que determinassem a matriz curricular para as escolas, a sua estipulação não ficaria a cargo dos gestores, o que evitaria a exclusão de muitos alunos ao acesso a língua estrangeira. Vale lembrar que isso acontece especificamente na matriz curricular das oficinas das escolas de tempo integral de ensino fundamental I.

Nessa perspectiva, Freitas (2010, p. 211), apoiada em Rocha (2006), ressalta a inexistência de parâmetros oficiais específicos para o ensino de línguas nos anos inicias do ensino fundamental brasileiro, resultado de sua inclusão facultativa, o que, além de sustentar os mecanismos de exclusão, não deixa claro quem deve se responsabilizar por ele, levando à forma desconexa pela qual tal ensino tem se difundido nas escolas públicas.

Isso é confirmado por Rocha (2006):

(...) é pertinente mencionar que a inclusão facultativa do ensino de línguas estrangeiras nos ciclos iniciais do Ensino Fundamental resulta na inapetência por parâmetros oficiais específicos para o mesmo. Tal fato compromete $o$ processo de ensino-aprendizagem de LE para crianças de $1^{\mathrm{a}}$ a $4^{\mathrm{a}}$ séries, o qual vem sendo implantado em várias escolas públicas brasileiras, apesar de sua não obrigatoriedade. A inexistência de diretrizes norteadoras para o ensino de LE nos ciclos 1 e 2 do Ensino Fundamental, decorrente do fato de ser esse ensino facultativo, compromete-o seriamente, uma vez que objetivos claros e diretrizes teórico-práticas consistentemente desenvolvidas são condições essenciais para que o mesmo seja bem sucedido (JOHNSTONE, 2002; CAMERON, 2001, 2003; entre outros). (ROCHA, 2006, p. 7-8).

Atualmente o Estado conta com aproximadamente 1150 escolas de ensino fundamental, das quais apenas 314 são escolas de tempo integral e oferecem o ensino de língua inglesa para seus alunos. ${ }^{2}$

Com isso, e ao estudarmos as normas aplicadas ao currículo do ensino fundamental I, podemos concluir que os alunos desse ciclo estão sendo privados do ensino das aulas de língua estrangeira. Isso resulta em desníveis linguísticos quando esses alunos ingressarem no ensino fundamental (ciclo II), pois uma parte destes vêm de escolas que oferecem as oficinas, e outros de escolas que não as oferecem.

Os possíveis desníveis podem gerar questionamentos de pais e alunos em relação à discrepância existente, o que naturalmente provocará a necessidade de se apurar o porquê 
de algumas escolas oferecerem as oficinas de inglês e outras não, uma vez que pertencem à mesma rede de ensino.

No que diz respeito à metodologia, observa-se que as diretrizes de atividades organizadas para a Oficina Curricular de Inglês - ciclo I, da Escola Tempo Integral (ETI), assevera para a ênfase comunicativa das atividades: "lembramos que qualquer que seja a unidade, e/ou tema, o ensino de inglês deve privilegiar a comunicação com ênfase na oralidade". Ressalta ainda que, pela sua importância, essa diretriz deve ser vivenciada em todas as oficinas, independentemente do ano e do tema em questão.

Por outro lado, o Currículo do Estado de São Paulo (2011, p. 110) afirma que a orientação fundamentada no letramento se sustenta nas relações existentes entre os princípios anteriormente polarizados, propondo a articulação: entre o saber e o fazer, entre o sistema linguístico e a língua em uso, entre a oralidade e a escrita, entre o aprender e a reflexão sobre a própria aprendizagem.

Com isso, ainda sobre a abordagem metodológica, observamos que as orientações propostas pelas Diretrizes da Escola Tempo Integral (DEETI), não estão em consonância com o que preconiza o documento do Currículo do Estado de São Paulo, uma vez que não apresenta uma visão de linguagem como prática social, que destaca os letramentos múltiplos, de acordo com os gêneros tomados como objetos de ensino.

Observa-se que as Diretrizes de Ensino da Escola Tempo Integral organizam suas temáticas com acentuado teor conteudista, na medida em que se voltam visivelmente à cobertura de vocabulário. $\mathrm{O}$ documento propõe ainda que as unidades sejam divididas em três partes distintas: Words to Learn (foco na aquisição de vocabulário), Talking Time (produção oral de diálogos) e Storage (realização de atividades).

Em consequência dessa orientação para o desenvolvimento das aulas de língua inglesa, os alunos são expostos à aquisição de vocabulário e a diálogos dissociados de gêneros discursivos, restringindo sua proximidade com as orientações e práticas de natureza sóciointeracionista.

Conforme observado na sugestão de atividade pelas diretrizes (SÃO PAULO, 2007, p. 17), na figura 1:

\section{ETI KIDS 3 - UNIT 2 - FOOD AND DRINKS}

Objective: Citar as comidas e bebidas favoritas; oferecer comida e bebida; descrever o que se come e bebe nas diferentes refeicões do dia (hábitos alimentares).

Topic: Comidas e bebidas.

\begin{tabular}{|c|c|c|}
\hline Words to Learn & Talking Time & Storage \\
\hline \begin{tabular}{|l} 
Different types of food: \\
hamburger / \\
hot dog / sandwich / beef / rice / \\
beans / fries / salad / spaghetti / \\
fruit / ice-cream / chocolate cake / \\
bread / butter / cookies. \\
Different types of drinks: water / \\
juice / soda / coke / milk / coffee \\
Breakfast / lunch / snack / dinner
\end{tabular} & $\begin{array}{l}\text { Dialogue A } \\
\text { A: What is your favorite food? } \\
\text { B: Oh, I love hamburger/ fries. And you? } \\
\text { A: I like beef/ spaghetti. } \\
\text { Dialogue B } \\
\text { A: What is your favorite drink? } \\
\text { B: Oh, I love coke. And you? } \\
\text { A: I like juice. } \\
\text { Dialogue C } \\
\text { A: What do you have for lunch? } \\
\text { B: Rice and beans and water. } \\
\text { Dialogue D } \\
\text { A: Do you want some coffee? } \\
\text { B: Yes, please or No, thank you. }\end{array}$ & $\begin{array}{l}\text { Activities: } \\
4,13, \\
17 \text { e } 28\end{array}$ \\
\hline
\end{tabular}


Em contraponto, observamos uma atividade sugerida para o sétimo ano do ensino fundamental conforme o currículo, na figura 2:

\section{WHAT'S IN THE FOOD YOU EAT?}

1. Tick $(\checkmark)$ the items that are junk food.
( ) hamburger
( ) rice and beans
( ) apple
( ) candy
( ) French fries
( ) water
( ) sodas
( ) chocolate cookies
Junk food $=$ food that is not healthy because it contains a
lot of calories, fat, sugar etc.
and little nutritional value.

2. Look at the tables below and answer the questions.

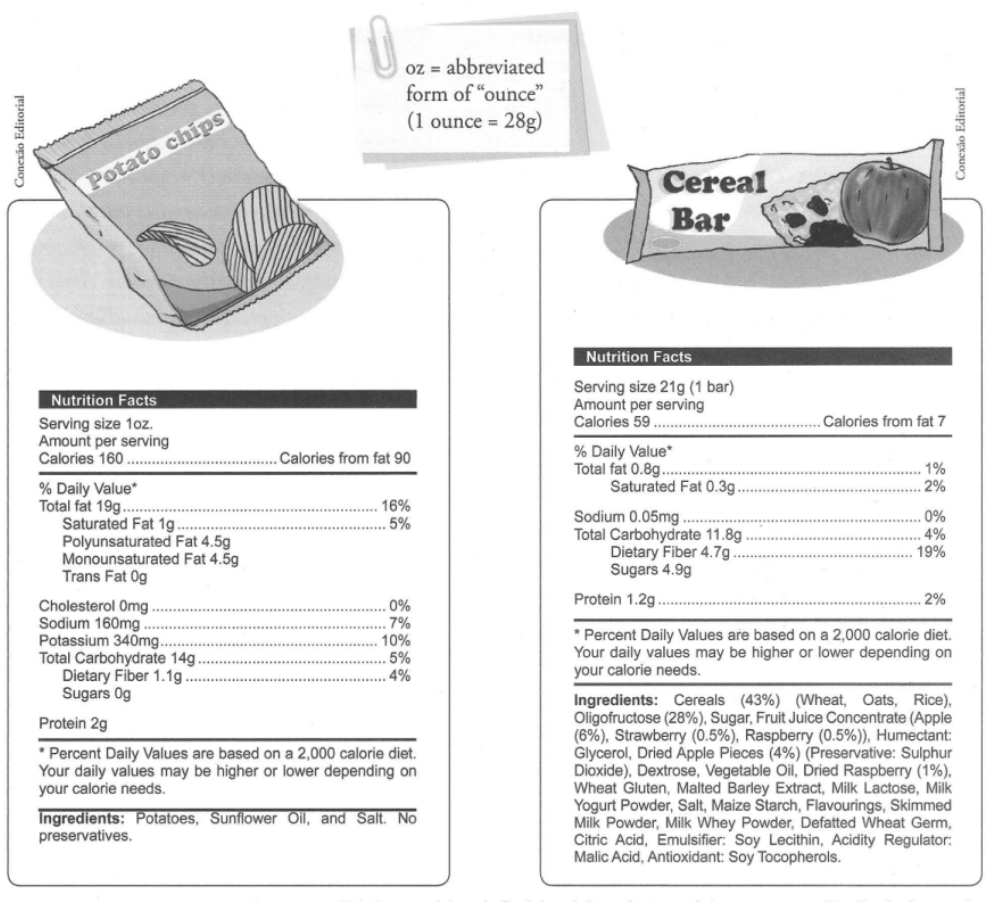

Tabelas nutricionais ficticias elaboradas especialmente para o São Paulo faz escolo.

Figura 2: Caderno do aluno - $7^{\text {a }}$. Série, SEE 2009, p. 30

Com todo o exposto, observa-se um distanciamento nas diretrizes curriculares para o desenvolvimento das aulas de língua inglesa dentro da mesma rede de ensino. É preciso que se criem políticas públicas que se harmonizem às dinâmicas cotidianas das escolas, para que não existam discrepâncias e prejuízos para os alunos.

\section{O desenho da pesquisa}

Com o objetivo de entender os desafios enfrentados por docentes que atuam nas oficinas de língua inglesa, das escolas de tempo integral que atendem crianças nos anos iniciais do Ensino fundamental, foi realizada, como instrumento de coleta de dados, entrevista com questões semiestruturadas. A pesquisa envolveu três escolas e três professoras pertencentes à mesma diretoria de ensino, que atuavam, no ano de 2013, em escolas de tempo integral da rede estadual de ensino, na região leste da capital de São Paulo.

Para análise das entrevistas foram adotados os direcionamentos de Szymanski (2004, p. 72): "o pesquisador deve estar atento não só à fala de seu entrevistado, mas também ao seu meio. Este inclui os diversos aspectos do ambiente físico e social, e 
também as interações que o entrevistado estabelece durante a situação de entrevista".

Para apresentação e análise dos dados, foram identificadas algumas categorias, cuja análise contribuiu com o estudo do objeto. Franco (2008) destaca a importância de elencar categorias relevantes para que se forneçam resultados férteis para a pesquisa, segundo a autora:

(...) um conjunto de categorias é produtivo desde que concentre a possibilidade de fornecer resultados férteis. Férteis em índices de inferências, em hipóteses novas e em dados relevantes para o aprofundamento de teorias e para a orientação de uma prática crítica, construtiva e transformadora. (FRANCO, 2008, p. 68).

Neste artigo foram focadas apenas quatro dessas categorias: ensino de língua estrangeira nos anos iniciais; grau de interesse dos alunos nas atividades das aulas; estratégias de ensino utilizadas pelas professoras; e o ensino de língua estrangeira e equidade social.

\section{Discussão dos resultados}

Sobre o papel da língua inglesa nas oficinas das Escolas de Tempo Integral, a categoria "o ensino de língua estrangeira nos anos iniciais do ensino fundamental", revelou na fala das professoras a importância do idioma:

\footnotetext{
“(...) desenvolver a criticidade dos alunos ampliando a sua visão de mundo em forma de interação, num jornal, na internet, articular os conteúdos da oficina com a vivência deles." (Ana, 11/09/2013).

"Conhecimento lexical, textual, ouvir e entender o que os outros falam, falar bem em muitas situações, conhecimentos de situações em inglês contextualizadas e visão de linguagem enquanto prática social.” (Carla, 09/10/2013).
}

As falas das professoras confirmam os estudos de Rocha (2006), Santos (2005), Tonelli (2010) e Cameron (2001), que convergem para o fato de que expor a criança ao aprendizado de outra língua favorece os desenvolvimentos linguístico, cognitivo, afetivo, sociocultural, além de colaborar para uma aprendizagem efetiva em séries posteriores.

Segundo Santos (2010), por terem já aprendido uma língua, as crianças trazem para a aula de LE grande variedade de experiências de linguagem, de vida e de outras habilidades naturais que as ajudam no aprendizado, e que não podem ser ignoradas pelo professor. Ambas as línguas, a materna e a estrangeira, podem ser desenvolvidas paralelamente.

Outro aspecto ressaltado por uma das professoras entrevistadas foi o fato de que o aluno, quando aprende um idioma, associar, de alguma maneira, a nova língua à materna, e com isso, mais bem desenvolver-se nas duas línguas.

Com isso, confirmamos a afirmação de Rivers (1975), de que as crianças entre 4 e 10 anos de idade têm maior flexibilidade em aprender uma língua estrangeira, porque as estruturas da língua materna ainda não foram solidificadas, e, assim, não ocorrem interferências na segunda língua que está em processo de aprendizagem.

Outra categoria levantada foi o grau de interesse dos alunos nas aulas de língua inglesa. Com base na análise das entrevistas, as professoras apontam que a maioria dos alunos apresentam grande motivação e desinibição nas aulas de língua inglesa, conforme 
se verifica: "Eu acho que a grande maioria tem interesse $\operatorname{sim}(. .$.$) , os pequenininhos acham$ tudo muito interessante, uma descoberta (...)" - Ana (11/09/2013); “(...) eles têm um interesse muito grande, eles ficam contando com a chegada da aula" - Carla (09/10/13).

Referente aos depoimentos citados, Cameron (2002) e Yule (1997) confirmam que o que favorece o aprendizado de uma língua estrangeira é o baixo nível de inibição apresentado pelas crianças, quando expostas a outra língua. Para esses autores, essa característica, entre outros fatores, facilita a aquisição de uma melhor pronúncia no idioma na medida em que as suas habilidades linguísticas se desenvolvem.

“(...) é a fase em que eles mais se sentem motivados, eles não têm vergonha na hora de falar, eles não ficam criticando. Isso é diferente dos outros maiores. Porque quando eles são maiores, o que acontece? Se eles falam alguma coisa errada, os outros, vão rir, vão gozar deles. Já os pequenos não têm isso, errou, eles falam de novo e se torna uma brincadeira (...)" (Beatriz, 11/09/2013).

Não obstante, as professoras relataram aspectos que prejudicam o interesse dos alunos durante as aulas, como, por exemplo, alunos que ainda não sabem ler e escrever, o medo de errar, a falta de acompanhamento e incentivo dos pais.

“(...) eu acho que existem outros fatores, não só na aula de inglês, que faz com que o aluno não se sinta interessado na sala de aula. Eu acho que esse é um deles, às vezes, um aluno que está no $5^{\circ}$ ano não saber ler nem escrever. Então, como é que ele vai compreender se ele não sabe a base?" (Ana, 11/09/2013)

O depoimento citado demonstra que a professora acredita ser impossível que o aluno tenha motivação, uma vez que ele não compreende nem mesmo sua língua materna.

Contradizendo esse pensamento, Santos (2010) assevera que ambas as línguas podem ser desenvolvidas paralelamente, ou seja, não há necessidade de se negligenciar a LM (língua materna) para se "abrir caminho" para outra.

Um dos pontos mais presentes nas falas das professoras foram as estratégias de ensino utilizadas pelos professores. As entrevistas revelaram que a dinâmica e recursos das aulas de língua estrangeira para crianças devem envolver o lúdico, músicas e atividades que fazem parte do contexto dos alunos.

\footnotetext{
"Eu tento fazer com que os conteúdos fiquem bem firmes com a prática deles do dia a dia. Porque, senão, não tem um significado para eles, se não estiver de acordo com a prática deles. (...) Os assuntos, os temas, e os conteúdos que eu escolho lá são todos contextualizados com a realidade deles.” (Ana, 11/09/2013).
}

Conforme confirmado por Lima (2008), o aluno aprenderá a LE de maneira mais fácil se ele conseguir construir sentidos com esta. No entanto, para que isso ocorra, é necessário que a aprendizagem seja significativa para os alunos, e uma das maneiras de promover atividades relevantes é trabalhar tópicos familiares para eles, levando em consideração suas experiências de vida.

No depoimento de uma das professoras ouvidas foi verificada a importância do uso de desenhos e músicas nas aulas de língua inglesa.

Eu costumo desenhar bastante na lousa, é uma forma de fazer com que os alunos memorizem bastante. Quando eles veem o desenho, eles vão associar a 
palavra ao desenho e isso tem ajudado bastante. A música também ajuda muito porque, uma vez que eles aprendem uma música, e eu estou sempre cantando com eles, isso é uma forma de memorizar, e quando cai algum exercício que tem alguma palavra que consta na música que eles aprenderam, eles já vão diretamente (professora, lembrei que isso estava na música que aprendemos alguns meses atrás, e isso tem sido de grande ajuda). (Beatriz, 11/09/2013)

Outra professora, trouxe em sua fala, que os alunos aprendem de diferentes maneiras, sendo assim, devem ser utilizadas diversas abordagens para se atingir o mesmo objetivo.

(...) eu trouxe os joguinhos que tinham as alimentações, aí eu percebi que eles começaram a ter um pouco mais de interesse. Então, assim. Na sala de aula tem vários alunos e nem todos vão se interessar pelo modo que você está explicando. Então, você tem que tentar conquistá-los de diversas maneiras, então, uns eu conquisto pelos jogos, outros, eles ficam, eles gostam mais da lousa, de copiar, de fazer e de falar, outros são mais as músicas. Então, aí você consegue. São várias opções, tento fazer assim. (Ana, 11/09/2013)

Podemos perceber, segundo os depoimentos das professoras, que, dentre as várias atividades experimentadas, são as lúdicas e as músicas as preferidas dos alunos.

Com todo o exposto, podemos concluir que existem várias estratégias e recursos que podem ser utilizados como aliados no processo de ensino-aprendizagem nas aulas de língua inglesa. No entanto, cabe ao professor analisar as necessidades e refletir com consciência sobre o melhor caminho para atingir os seus objetivos.

No que se refere à categoria "ensino de língua estrangeira e equidade social", foi revelado nos discursos das professoras e nos documentos estudados, que o ensino de uma língua estrangeira contribui para a formação dos alunos, afim de que estes tenham acesso a uma educação de qualidade igualitária, que lhes permitam enfrentar os desafios do mundo atual.

Nessa perspectiva, Cope e Kalantzis (2000), e Rocha (2009), asseveram que a aprendizagem de uma segunda língua é fator determinante para a inclusão social, que constitui passo importante no processo de redução das desigualdades. Como constatado, verifica-se também na normatização que organiza o sistema educacional no Brasil, que está fundamentada em princípios, entre eles, a equidade, que é a garantia de oportunidades educacionais iguais para todos.

\section{Considerações finais}

A língua inglesa, no ensino fundamental I, se insere na perspectiva de ampliação de oportunidades, conhecimento de outros povos e culturas para as crianças que têm acesso a esse ensino.

A esse propósito, a pesquisa ora desenvolvida buscou, à luz dos estudiosos do tema, das políticas públicas e das falas das professoras, entender a importância e o papel da língua inglesa nas escolas de tempo integral, e com isso apontar razões para que se inclua a disciplina na matriz curricular no EFI.

Nesta pesquisa também foi constatado um distanciamento das orientações metodológicas para o ensino de língua estrangeira (ciclo I), contidos nas Diretrizes de Ensino das Escolas de Tempo Integral, e as orientações presentes no Currículo do Estado de São Paulo - ensino fundamental (ciclo II) e ensino médio. As diferenças evidenciadas 
não corroboram com a visão de linguagem apresentadas nos estudos desta pesquisa, nem com a visão preconizada pelo Currículo do Estado de São Paulo, que destaca a ênfase nos letramentos múltiplos.

As entrevistas com as professoras indicaram que o ensino língua inglesa desperta grande interesse nas crianças dos anos iniciais, que em sua maioria, possuem grande motivação para o aprendizado. Outro fator mencionado pelas docentes foi o grau de desinibição desses alunos, uma característica preponderante das crianças que colabora no aprendizado de línguas. Também foi possível compreender que as atividades lúdicas, que envolvam jogos e músicas, facilitam o ensino e possibilitam uma aprendizagem significativa.

A fala das professoras revelou ainda que as crianças aprendem e desenvolvem a língua não apenas sentadas em suas carteiras, mas a partir das interações sociais estabelecidas nos usos significativos da língua.

Não obstante, a pesquisa mostrou alguns fatores que não contribuem para que o ensino de línguas seja efetivo nas Escolas de Tempo Integral da rede estadual: a falta de recursos didáticos para alunos e professores, e a falta de formação específica para os professores que atuam nos anos iniciais, uma vez que estes professores não são pedagogos.

Ainda sobre o ensino de língua inglesa nos anos iniciais, a pesquisa mostrou que uma quantidade significativa de escolas está excluída desse projeto, e, com isso, deixam de ofertar o ensino da língua estrangeira em sua grade curricular. Com a Resolução SE $\mathrm{n}^{\mathrm{o}} 3$, de 16 de janeiro de 2014, o sistema estadual deu um passo significativo, ao criar a possibilidade de ampliação do ensino da língua inglesa na matriz curricular das escolas de ciclo I do Estado de São Paulo. Contudo o problema da garantia a todos não foi resolvido, pois ficou a cargo do diretor das respectivas unidades escolares adotá-la ou não.

Como o Estado tem o papel de garantir o acesso ao ensino de qualidade a todos, esta pesquisa veio sinalizar que o ensino de língua inglesa merece ampliar o seu alcance, de modo que atinja a todos os alunos, para que não apenas alguns possam ser preparados para enfrentar os desafios do mundo atual, e formar uma base sólida para prosseguir nos estudos posteriores.

Pelos estudos realizados, ficou evidente que o aprendizado de uma língua estrangeira constitui um passo importante no sentido da equidade social, contudo, a garantia de aprendizagem de outra língua depende de vários fatores, cuja dinâmica desenvolvida no Estado ainda não contempla.

\section{Referências}

ALMEIDA FILHO, J. C. P. Dimensões Comunicativas no Ensino de Línguas. Campinas: Pontes Editores, 1993.

CAMERON, L. Teaching English to Young Learners. Cambridge: Cambridge University Press, 2001.

Coordenadoria de Estudos e Normas Pedagógicas (CENP) Disponível em: $<$ http://cenp. edunet.sp.gov.br/escola_integral/2007/>. Acesso em 18 mai. 2013.

COPE, B.; KALANTZIS, M. (Eds.). Multiliteracies: Literacy Learning and the Design of Social Futures. London: Routledge, 2000.

LIMA, A. P. A prática de ensino e a formação de professores de inglês para crianças. 
In: ROCHA, C. H.; TONELLI, J. R. A.; SILVA, K. A. (Org.) Língua Estrangeira para Crianças: Ensino-Aprendizagem e Formação Docente. Campinas: Pontes Editores, 2010.

RIVERS, W. M. (1975). A metodologia do ensino de línguas estrangeiras. São Paulo: Pioneira. (Tradução de: Teaching Foreign Language Skills. Chicago, 1968)

ROCHA, C. H.; TONELLI, J. R. A.; SILVA, K. A. (Org.) Língua Estrangeira para Crianças: Ensino-Aprendizagem e Formação Docente. Campinas: Pontes Editores, 2010.

Provisões para Ensinar LE no Ensino Fundamental de $1^{\text {a }}$ a $4^{\mathrm{a}}$ Séries: dos Parâmetros Oficiais e Objetivos dos Agentes. Dissertação (Mestre) - Instituto de Estudos da Linguagem, Universidade Estadual de Campinas, Campinas, 2006.

O ensino de LE (inglês) para crianças do ensino fundamental público na transdisciplinaridade da Linguística Aplicada. In: TONELLI, J. R. A.; RAMOS, S. G. M. O ensino de LE para crianças: reflexões e contribuições. Londrina: Moriá, 2007.

O ensino de línguas para crianças: refletindo sobre princípios e práticas. In: ROCHA, C. H.; BASSO, E. A. (Orgs.). Ensinar e aprender língua estrangeira nas diferentes idades: reflexões para professores e formadores. São Carlos: Claraluz, 2008.

Propostas para o inglês no ensino fundamental I público: plurilinguismo, transculturalidade e multiletramentos. Tese (Doutorado) - Instituto de Estudos da Linguagem, Universidade Estadual de Campinas, 2010.

SANTOS, L. I. S. Presença de LE na Sociedade e em Contexto de Ensino Regular Público. In: SILVA, K. A.; C. H. ROCHA; TONELLI, J. R. A. (Org.) Língua estrangeira para crianças: ensino-aprendizagem e formação docente, p. 149-184. Campinas, SP: Pontes, 2010.

Crenças acerca da inclusão da língua inglesa nas séries iniciais: quanto antes melhor? Cuiabá, MT. Dissertação de Mestrado. Universidade Federal de Mato Grosso, 2005.

Língua inglesa em anos iniciais do ensino fundamental: fazer pedagógico e formação docente. São José do Rio Preto, 2009.

SZYMANSKI, H. Entrevista na Pesquisa em Educação: a prática reflexiva. Brasília, DF: Líber livro, 2004.

TONELLI, J. R. A.; RAMOS, S. G. M. O ensino de LE para crianças: reflexões e contribuições. Londrina: Moriá, 2007.

YULE, G. The study of language. 2ed. United States: Cambridge University Press, 1997. 